\title{
Synthesis and Characterization of Soluble Aromatic Polyamides Derived from Diamines with the 4,5-Imidazolediyl Structure
}

\author{
Fumihiko Akutsu, ${ }^{\dagger}$ Mari Inoki, Mamoru Sawano, Yoshio Kasashima, \\ Kiyoshi Naruchi, and Masatoshi Miura \\ Department of Applied Chemistry, Faculty of Engineering, Chiba University, \\ Yayoi-cho 1-33, Inage-ku, Chiba 263-8522, Japan
}

(Received March 30, 1998)

\section{KEY WORDS Aromatic Polyamides / Solubility / Thermal Properties /}

The introductions of the rigid, zigzag, bulky, and polar units to the backbone of aromatic polyamides improves solubility while maintaining high thermal resistance, ${ }^{1-7}$ but improvement is not satisfactory. We previously demonstrated that the introduction of the rigid, zigzag, bulky, and polar 2-methyl-4,5-di(1,3-phenylene)imidazole unit or 2-phenyl-4,5-di(1,3-phenylene)imidazole unit to the backbone of aromatic polyimides improves solubility without decreasing high thermal resistance. ${ }^{8}$ In the present study, novel aromatic polyamides with their structures were investigated. As shown in Scheme 1, polyamides I, II, and III were synthesized from the diamines such as 4,5-di(3-aminophenyl)imidazole (1), 4,5-di(3-aminophenyl)-2-methylimidazole (2), and 4,5di(3-aminophenyl)-2-phenylimidazole (3), which were prepared as the monomer for the polyimide synthesis, ${ }^{8}$ and their solubility and thermal properties were examined. Introductions of the 4,5-di(1,3-phenylene)imidazole units increase polarity and bulkiness, and make the backbone of polyamide zigzag maintaining rigidity. As shown in Scheme 2, aromatic polyamides II', the isomers of polyamides II, were prepared from novel diamine 4,5-di(4-aminophenyl)-2-methylimidazole (5), and their properties were compared with those of polyamides II.

\section{RESULTS AND DISCUSSION}

\section{Polyamide Synthesis}

Polyamides I, II, and III were synthesized by lowtemperature solution polycondensation ${ }^{9}$ of diamines $\mathbf{1}$, $\mathbf{2}$, and $\mathbf{3}$ with several aromatic diacyl chlorides, such as isophthaloyl dichloride (4a), terephthaloyl dichloride (4b), and 4,4'-biphenyldicarbonyl dichloride (4c), respectively. The results are summarized in Table I (runs 114). The effect of acid acceptor was investigated on the polymerization of Ia, Ib, Ic, IIa, and IIIa. Except for the polymerization of IIa (run 7), lithium carbonate as the acid acceptor afforded better results than methyl oxirane. Thus, other polymerizations were carried out using lithium carbonate. All polyamides were obtained in the yield above $88 \%$, and inherent viscosity ranged from 0.26 to $1.24 \mathrm{dl} \mathrm{g}^{-1}$.

5 was prepared by the reduction of 2-methyl-4,5-di(4nitrophenyl)imidazole ${ }^{10}$ (6). A characteristic chemical

\footnotetext{
$\dagger$ To whom correspondence should be addressed
}

shift near 12 ppm resulting from imidazole $\mathrm{N}-\mathrm{H}$ was not observed in the ${ }^{1} \mathrm{H}$ NMR spectrum of the product in dimethyl sulfoxide- $d_{6}$ (DMSO- $d_{6}$ ). ${ }^{1} \mathrm{H}$ NMR spectrum of 2-methylimidazole was also measured in DMSO- $d_{6}$. Similarly, no chemical shift near $12 \mathrm{ppm}$ was observed in the ${ }^{1} \mathrm{H}$ NMR spectrum. Therefore, the product was identified as diamine $\mathbf{5}$ by elemental analysis and other spectroscopic data such as ${ }^{13} \mathrm{C}$ NMR and IR spectroscopy.

Polyamides II' were prepared by low-temperature solution polycondensation, and the results are summarized in Table I (runs 15-20). When methyl oxirane was used as the acid acceptor (runs 15, 17, 19), the inherent viscosity of the obtained polyamide was higher than that of the polyamide synthesized by the corresponding polymerization using lithium carbonate (runs 16, 18, 20). These results were different from those of the polymerizations of I, II, and III, but the reason is not clear. Thus, polyamides $\mathbf{I I}^{\prime}$ were afforded in the yield above
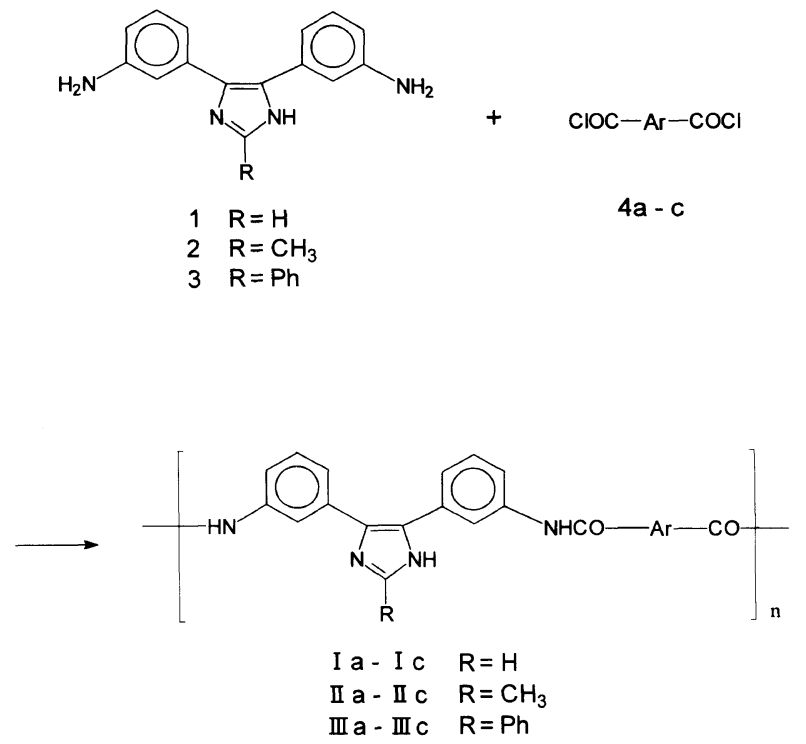

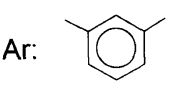

a

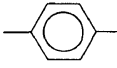

b

Scheme 1.

Scheme 1.

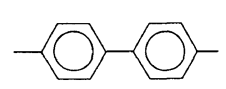

c 


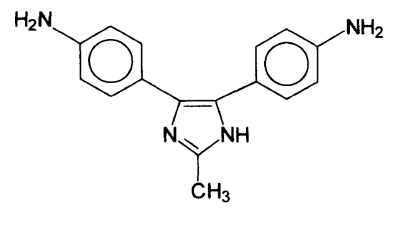

$+\quad \mathrm{ClOC}-\mathrm{Ar}-\mathrm{COCI}$
$4 \mathrm{a}-\mathrm{C}$

5
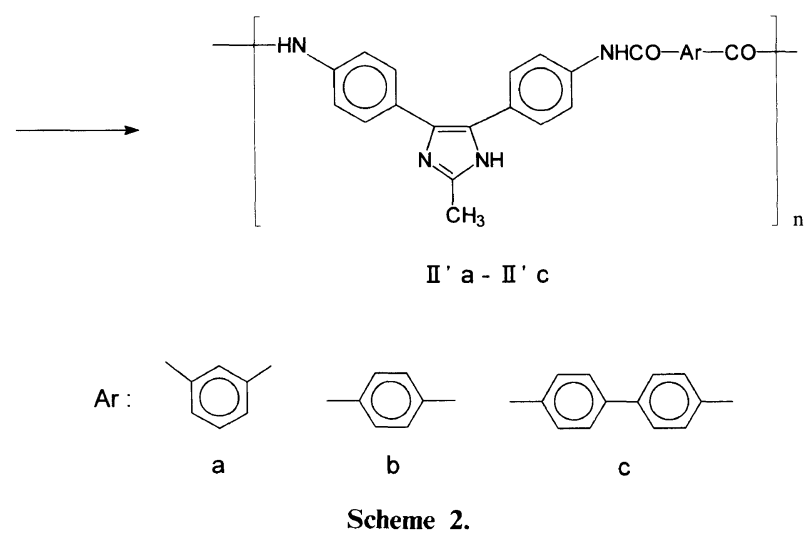

Table I. Results of polyamide preparations ${ }^{\mathrm{a}}$

\begin{tabular}{|c|c|c|c|c|}
\hline \multirow{2}{*}{ Run } & \multirow{2}{*}{ Polymer } & \multirow{2}{*}{$\begin{array}{c}\text { Acid } \\
\text { acceptor }^{b}\end{array}$} & \multirow{2}{*}{$\frac{\text { Yield }}{\%}$} & \multirow{2}{*}{$\frac{\eta_{\text {inh }}{ }^{\mathrm{c}}}{\mathrm{dl} \mathrm{g}^{-1}}$} \\
\hline & & & & \\
\hline 1 & Ia & MO & 96 & 0.42 \\
\hline 2 & Ia & $\mathrm{Li}_{2} \mathrm{CO}_{3}$ & 97 & 1.24 \\
\hline 3 & Ib & MO & 96 & 0.15 \\
\hline 4 & Ib & $\mathrm{Li}_{2} \mathrm{CO}_{3}$ & 97 & 0.45 \\
\hline 5 & Ic & MO & 94 & 0.16 \\
\hline 6 & Ic & $\mathrm{Li}_{2} \mathrm{CO}_{3}$ & 95 & 0.93 \\
\hline 7 & IIa & MO & 90 & 0.69 \\
\hline 8 & IIa & $\mathrm{Li}_{2} \mathrm{CO}_{3}$ & 98 & 0.37 \\
\hline 9 & IIb & $\mathrm{Li}_{2} \mathrm{CO}_{3}$ & 94 & 0.26 \\
\hline 10 & IIc & $\mathrm{Li}_{2} \mathrm{CO}_{3}$ & 100 & 0.69 \\
\hline 11 & IIIa & MO & 88 & 0.39 \\
\hline 12 & IIIa & $\mathrm{Li}_{2} \mathrm{CO}_{3}$ & 97 & 0.40 \\
\hline 13 & IIIb & $\mathrm{Li}_{2} \mathrm{CO}_{3}$ & 98 & 0.49 \\
\hline 14 & IIIc & $\mathrm{Li}_{2} \mathrm{CO}_{3}$ & 97 & 0.52 \\
\hline 15 & II'a & MO & 93 & 0.30 \\
\hline 16 & II'a & $\mathrm{Li}_{2} \mathrm{CO}_{3}$ & 98 & 0.28 \\
\hline 17 & $\mathbf{I I}^{\prime} \mathbf{b}$ & MO & 92 & 0.47 \\
\hline 18 & II'b & $\mathrm{Li}_{2} \mathrm{CO}_{3}$ & 79 & 0.24 \\
\hline 19 & II'c & MO & 94 & 1.00 \\
\hline 20 & II'c & $\mathrm{Li}_{2} \mathrm{CO}_{3}$ & 98 & 0.53 \\
\hline
\end{tabular}

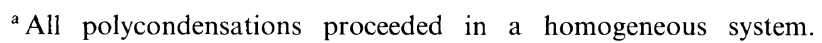
${ }^{\mathrm{b}} \mathrm{MO}$, methyl oxirane; $\mathrm{Li}_{2} \mathrm{CO}_{3}$, lithium carbonate. ${ }^{\mathrm{c}}$ Inherent viscosity, measured in conc. sulfuric acid $\left(0.50 \mathrm{~g} \mathrm{dl}^{-1}\right)$ at $30^{\circ} \mathrm{C}$.

$92 \%$, and inherent viscosity ranged between 0.30 and $1.00 \mathrm{dl} \mathrm{g}^{-1}$.

\section{Thermal Properties of Polyamides}

The thermal properties of the polyamides are summarized in Table II. Polyamides I, II, and III showed high $T_{\mathrm{g}}$ s ranging from 275 to $304^{\circ} \mathrm{C}$ although having the zigzag and bulky structures. In each series of the polyamides, $T_{\mathrm{g}}$ decreased in the following order: $\mathbf{c}>\mathbf{b}>\mathbf{a}$, depending on symmetry and rigidity of the carboxylic acid unit of the polyamides. There was little difference between $T_{\mathrm{g}} \mathrm{s}$ of I, II, and III. $T_{\mathrm{g}}$ of the polyamide derived from bis(4-aminophenyl)ether and isophthaloyl dichlo-
Table II. Thermal properties of polyamides

\begin{tabular}{|c|c|c|c|c|c|}
\hline $\operatorname{Run}^{\mathrm{a}}$ & Polymer & $\frac{T_{\mathrm{g}}^{\mathrm{b}}}{{ }^{\circ} \mathrm{C}}$ & $\frac{T_{\mathrm{d}}^{\mathrm{c}}}{{ }^{\circ} \mathrm{C}}$ & $\frac{T_{\mathrm{d} 10}{ }^{\mathrm{d}}}{{ }^{\circ} \mathrm{C}}$ & $\begin{array}{c}\text { Weight residue } \\
\text { at } 600^{\circ} \mathrm{C} / \%\end{array}$ \\
\hline 2 & Ia & 275 & 387 & 511 & 81 \\
\hline 4 & Ib & 284 & 394 & 498 & 71 \\
\hline 6 & Ic & 287 & 408 & 514 & 73 \\
\hline 7 & IIa & 288 & 413 & 470 & 72 \\
\hline 9 & IIb & 293 & 389 & 473 & 77 \\
\hline 10 & IIc & 304 & 433 & 487 & 75 \\
\hline 12 & IIIa & 284 & 412 & 480 & 69 \\
\hline 13 & IIIb & 298 & 439 & 489 & 62 \\
\hline 14 & IIIc & 303 & 456 & 494 & 63 \\
\hline 15 & II'a & 329 & 396 & 473 & 67 \\
\hline 17 & $\mathbf{I I}^{\prime} \mathbf{b}$ & 337 & 413 & 483 & 66 \\
\hline 19 & II'c & 337 & 433 & 501 & 72 \\
\hline
\end{tabular}

a Sample run numbers appear in Table I. ${ }^{\text {b }}$ Glass transition temperature, observed by DSC in a nitrogen atmosphere; heating rate, $10 \mathrm{~K} \mathrm{~min}^{-1}$. ${ }^{\mathrm{c}}$ Thermal decomposition temperature, observed by TGA in a nitrogen atmosphere. ${ }^{\mathrm{d}}$ Temperature at $10 \%$ weight loss, observed by TGA in a nitrogen atmosphere. ${ }^{\mathrm{e}}$ Observed by TGA.

ride (polyamide IV) is known to be $260^{\circ} \mathrm{C} .^{1} T_{\mathrm{g}} \mathrm{s}$ of Ia, IIa, and IIIa were $c a .15-25^{\circ} \mathrm{C}$ higher than that of IV, respectively. Thus, the introduction of the 4,5-di(1,3phenylene)imidazole unit to the main chain of polyamide increased $T_{\mathrm{g}}$. This is attributed to the dipole-dipole interaction between the polar imidazole units introduced.

$T_{\mathrm{d}} \mathrm{s}$ ranged from 387 to $456^{\circ} \mathrm{C}$, and $T_{\mathrm{d} 10} \mathrm{~s}$ from 470 to $514^{\circ} \mathrm{C}$. Weight residues at $600^{\circ} \mathrm{C}$ were above $62 \%$. Thus, polyamides I, II, and III exhibited high thermal stability. The thermal stability of III was expected to be higher than that of corresponding I because of the more highly phenylated structure of III. However, the $T_{\mathrm{d} 10} \mathrm{~s}$ of I were higher than those of corresponding III, and the weight residues of I were also higher than those of corresponding III. Probably, scission of the bonding between the imidazole ring and the pendant phenyl group may be somewhat easy, since the imidazole ring is not coplanar to the pendant phenyl group.

$T_{\mathrm{g}} \mathrm{s}$ of $\mathbf{I I}^{\prime}$ were quite high, $\mathrm{ca} .330^{\circ} \mathrm{C}$. $T_{\mathrm{d}} \mathrm{s}$ ranged from 396 to $433^{\circ} \mathrm{C}, T_{\mathrm{d} 10} \mathrm{~s}$ were above $473^{\circ} \mathrm{C}$, and weight residues at $600^{\circ} \mathrm{C}$ were above $66 \%$.

\section{Solubility of Polyamides}

Solubility in several organic solvents at $2.0 \%(\mathrm{w} / \mathrm{v})$ was examined at room temperature and at $80^{\circ} \mathrm{C}$. The results are listed in Table III. Some polyamides indicated good solubility for wholly aromatic polyamides. In particular, IIa was soluble in DMSO, formic acid, $N, N$-dimethylacetamide (DMAc) at room temperature, and $m$-cresol at $80^{\circ} \mathrm{C}$. It is known that polyamide IV is soluble in conc. sulfuric acid, DMAc, and pyridine at room temperature, but insoluble in $m$-cresol. ${ }^{1}$ The solubility of polyamides Ia, IIa, and IIIa was higher than that of $\mathbf{I V}$, respectively. Thus, the introduction of the 4,5-di(1,3-phenylene)imidazole units to the polyamide backbone has effect on improvement of the solubility without sacrificing high thermal resistance. The solubility of I did not differ from that of II and III, respectively.

X-Ray diffraction patterns showed that polyamides $\mathbf{I}$, II, and III are all amorphous. It is considered that the introduction of the rigid and zigzag 4,5-di(1,3-phenylene)imidazole structure led to the amorphous nature. 
Table III. Solubilities ${ }^{\mathrm{a}}$ of polyamides

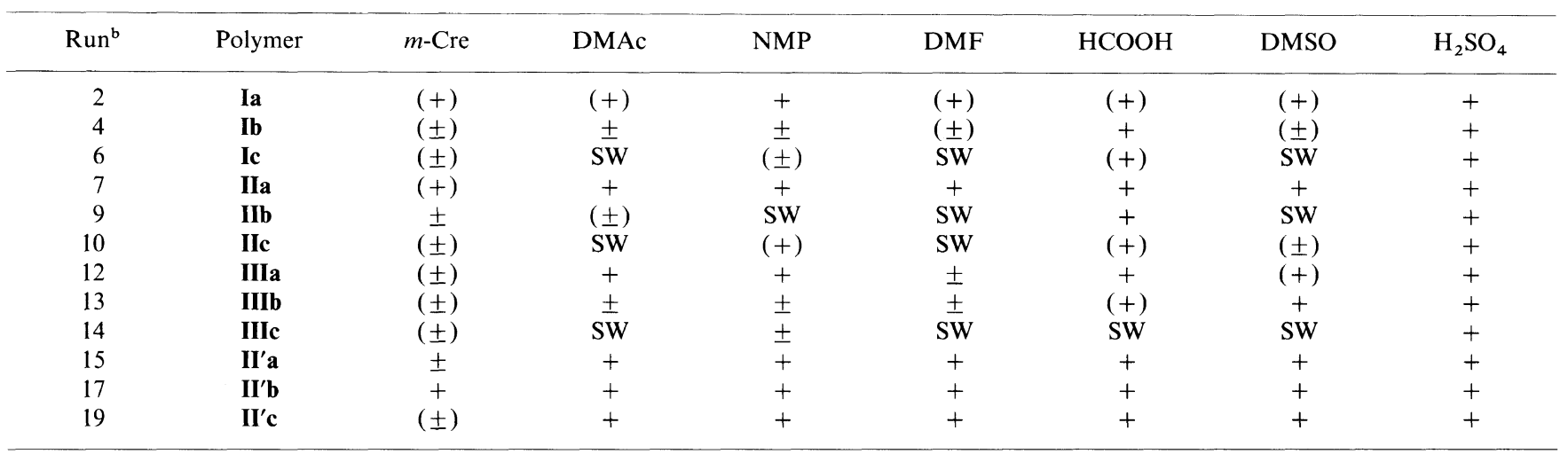

${ }^{a}$ Measured at $2.0 \%(\mathrm{w} / \mathrm{v})$. Data in parentheses were obtained during heating. The symbols have the following meanings:,+ soluble; \pm , partially soluble; -, insoluble; SW, swelling. ' ${ }^{2}$ Sample run numbers appear in Table I. $m$-Cre, $m$-cresol; DMAc, $N, N$-dimethylacetamide; NMP, 1-methyl-2-pyrrolidone; DMF, $N, N$-dimethylformamide; $\mathrm{HCOOH}$, formic acid; DMSO, dimethyl sulfoxide.

One factor for improved solubility is the amorphous nature of the polyamides.

Polyamides II'a and II'c were soluble in DMSO, formic acid, $N, N$-dimethylformamide (DMF), 1-methyl-2-pyrrolidone (NMP), and DMAc at room temperature. II'b was soluble in $m$-cresol as well. Thus, polyamides II' also possessed high thermal resistance and excellent solubility. The properties of 'I' were compared with those of isomeric II. Each $T_{\mathrm{g}}$ of $\mathbf{I I}^{\prime}$ was $\mathrm{ca} .30^{\circ} \mathrm{C}$ higher than that of corresponding II. The solubility of II' in all cases was also much higher than that of corresponding II. Thus, the introduction of 2-methyl-4,5-di(1,4-phenylene)imidazole structure to the polyamide backbone was more effective not only in improving solubility but also in maintaining $T_{\mathrm{g}}$ than the introduction of 2-methyl-4,5di(1,3-phenylene)imidazole structure. Similar tendency was observed in case of aromatic polyimides. The polyimides derived from 4,5-di(4-aminophenyl)-2-phenylimidazole possessed higher $T_{\mathrm{g}} \mathrm{s}$ and better solubility than the corresponding polyimides derived from 3 . $^{8,11}$ The introduction of 1,4-phenylene moiety between an electron-withdrawing amide linkage and an electronwithdrawing imidazole ring may thus lead these two groups to attract electron each other, resulting in increasing polarity of the polyamide structure over all. Therefore, the higher polarity of polyamides II' may induce higher $T_{\mathrm{g}}$ and further improve solubility in aprotic polar solvents.

\section{Conclusions}

The introduction of the rigid, zigzag, bulky, and polar 4,5-di(1,3-phenylene)imidazole units to the polyamide backbone improves solubility while maintaining high thermal resistance. Polyamides II' possess higher $T_{\mathrm{g}} \mathrm{s}$ as well as better solubility in aprotic polar solvents than isomeric polyamides II.

\section{EXPERIMENTAL}

\section{Monomers}

Diamines 1, 2, and 3 were prepared according to the method previously reported. ${ }^{8}$ Aromatic diacyl dichlorides $4 a, 4 b$, and $4 \mathbf{c}$ were prepared by chlorination of the corresponding dicarboxylic acids using thionyl chloride and DMF, and recrystallized from dry ligroin or dry benzene. Diamine 5 was prepared by the reduction of 6 as follows.

Stannous chloride dihydrate $(21.0 \mathrm{~g}, 93 \mathrm{mmol})$ was dissolved in hydrochloric acid $(40 \mathrm{ml})$ on heating, and the solution was chilled to $-5^{\circ} \mathrm{C} .6(5.11 \mathrm{~g}, 15.8 \mathrm{mmol})$ was added gradually, and the mixture was stirred at room temperature for $1 \mathrm{~h}$, and at $50^{\circ} \mathrm{C}$ for $5 \mathrm{~h}$. The reaction mixture was chilled to $-20^{\circ} \mathrm{C}$ to precipitate. The product was collected by filtration, and dissolved in water $(100 \mathrm{ml})$. The solution was filtrated, poured into aqueous sodium hydroxide solution $(20 \mathrm{wt} \%, 400 \mathrm{ml})$, and stirred overnight. The product was collected by filtration again, washed with $\mathrm{NaOH}$ solution, and with water. The crude product was recrystallized from water adding activated charcoal to give pale brown needles. Yield 34\%. mp $230.1-231.0^{\circ} \mathrm{C}$. IR (KBr, disk) $3452,3384 \mathrm{~cm}^{-1}(\mathrm{Ar}-$ $\mathrm{NH}_{2}$ ). ${ }^{1} \mathrm{H}$ NMR $\left(400 \mathrm{MHz}, \mathrm{DMSO}-d_{6}\right): \delta=2.24(\mathrm{~s} ; 3 \mathrm{H}$, $-\mathrm{CH}_{3}$ ), 5.01 (s; broad, $4 \mathrm{H},-\mathrm{NH}_{2}$ ), 6.47 (d; $J=8.2 \mathrm{~Hz}$, $4 \mathrm{H}, \mathrm{Ar}-\mathrm{H}), 7.08(\mathrm{~d} ; J=8.3 \mathrm{~Hz}, 4 \mathrm{H}, \mathrm{Ar}-\mathrm{H}) .{ }^{13} \mathrm{C} \mathrm{NMR}$ (100 MHz, DMSO- $\left.d_{6}\right)$ : $13.8\left(-\mathrm{CH}_{3}\right), 113.7\left(\mathrm{Ar} \mathrm{C}^{3}\right), 121.7$ (imidazole $\mathrm{C}^{4}$ ), 127.9, 128.1 $\left(\mathrm{Ar} \mathrm{C}^{1}, \mathrm{C}^{2}\right), 142.2$ (imidazole $\left.\mathrm{C}^{2}\right)$, $147.1\left(\mathrm{Ar} \mathrm{C}^{4}\right)$. Anal. Calcd for $\mathrm{C}_{16} \mathrm{H}_{16} \mathrm{~N}_{4}(264.3)$ : C, $72.70 \%$; H, 6.10\%; N, $21.20 \%$. Found: C, $72.56 \%$; H, $6.16 \% ; \mathrm{N}, 21.20 \%$.

\section{Low-Temperature Solution Polycondensation}

A typical procedure (run 2) is as follows. 1 (1.001 g, $4.00 \mathrm{mmol}$ ) and $13.5 \mathrm{ml}$ of NMP were placed into a four-necked reaction tube equipped with a mechanical stirrer and a nitrogen gas inlet having a calcium chloride tube. After the mixture was chilled to $-20^{\circ} \mathrm{C}$, isophthaloyl dichloride $(0.812 \mathrm{~g}, 4.00 \mathrm{mmol})$ and $2.5 \mathrm{ml}$ of NMP were added. The reaction was carried out at $-20^{\circ} \mathrm{C}$ for $1 \mathrm{~h}$. Lithium carbonate $(0.296 \mathrm{~g}, 4.01 \mathrm{mmol})$ was added, and the reaction mixture was stirred at room temperature for $5 \mathrm{~h}$, diluted with NMP, and poured into aqueous methanol (1:1 by volume) for precipitation. The product was washed with hot water, and with hot methanol, and dried under reduced pressure at $200^{\circ} \mathrm{C}$. Yield $97 \% . \eta_{\text {inh }}=1.24 \mathrm{dl} \mathrm{g}^{-1}\left(0.50 \mathrm{~g} \mathrm{dl}^{-1}\right.$ in conc. sulfuric acid at $30^{\circ} \mathrm{C}$ ). IR (KBr) 1656, $1532 \mathrm{~cm}^{-1}$ (amide I, II). Anal. Calcd for $\left(\mathrm{C}_{23} \mathrm{H}_{16} \mathrm{~N}_{4} \mathrm{O}_{2}\right)_{n}(380.4)_{n}$ : C, $72.62 \% ; \mathrm{H}$, $4.24 \%$; N, $14.73 \%$. Found: C, 71.02\%; H, 4.16\%; N, $14.40 \%$.

Other polyamides were synthesized by a similar 
procedure.

\section{Measurements}

$T_{\mathrm{d}} \mathrm{s}, T_{\mathrm{d} 10} \mathrm{~s}$, and weight residues at $600^{\circ} \mathrm{C}$ were obtained by thermogravimetric analysis (TGA). (MAC Science TG-DTA 2000). $T_{\mathrm{g}} \mathrm{s}$ were determined by differential scanning calorimetry (DSC) (Rigaku DSC 8055D1). These thermoanalytical measurements were carried out under the following conditions: heating rate, $10 \mathrm{~K} \mathrm{~min}^{-1}$; in a nitrogen atmosphere. $T_{\mathrm{g}} \mathrm{s}$ were determined by second scannings. IR spectra were recorded on a Hitachi 270-30 spectrophotometer. Wide angle X-ray diffraction patterns were obtained for specimens on a Rigaku KG X-ray diffraction apparatus with $\mathrm{Cu}-K_{\alpha}$ radiation $(25 \mathrm{kV}, 10$ $\mathrm{mA}$ ) using virgin samples. ${ }^{1} \mathrm{H}$ NMR spectra $(400 \mathrm{MHz})$ and ${ }^{13} \mathrm{C}$ NMR spectra $(100 \mathrm{MHz})$ were recorded on a $400 \mathrm{MHz}$ JEOL JNM-LA 400 spectrometer.

\section{REFERENCES}

1. Y. Imai, N. N. Maldar, and M. Kakimoto, J. Polym. Sci., Polym. Chem. Ed., 23, 1797 (1985).

2. H.-J. Jeong, Y. Oishi, M. Kakimoto, and Y. Imai, J. Polym. Sci., Part A, Polym. Chem., 28, 3293 (1990)

3. H.-J. Jeong, M. Kakimoto, and Y. Imai, J. Polym. Sci., Part A, Polym. Chem., 29, 767 (1991).

4. H.-J. Jeong, A. Kobayashi, M. Kakimoto, and Y. Imai, Polym. J., 26, 99 (1994).

5. F. Akutsu, K. Matsuo, N. Naruchi, and M. Miura, Polym Commun., 30, 182 (1987).

6. F. Akutsu, M. Inoki, K. Araki, Y. Kasashima, K. Naruchi, and M. Miura, Polym. J., 29, 529 (1997).

7. F. Akutsu, M. Inoki, K. Sunouchi, Y. Sugama, Y. Kasashima, K. Naruchi, and M. Miura, Polymer, 39, 1637 (1998).

8. F. Akutsu, M. Inoki, M. Sawano, Y. Kasashima, K. Naruchi, and M. Miura, Polymer, in press.

9. P. W. Morgan, "Condensation Polymers by Interfacial and Solution Methods" Interscience, New York, N.Y., 1965.

10. T. Van Es and O. G. Backberg, J. Chem. Soc., 1363 (1963).

11. F. Akutsu, T. Kataoka, H. Shimizu, K. Naruchi, and M. Miura, Macromol. Chem., Rapid Commun., 15, 411 (1994). 